\title{
THE RÔLE OF THYROXIN IODINE AND TOTAL ORGANIC IODINE IN THE CALORIGENIC ACTION OF WHOLE THYROID GLAND
}

\author{
By J. H. MEANS, J. LERMAN AND W. T. SALTER \\ (From the Thyroid Clinic of the Massachusetts General Hospital, and the \\ Huntington Memorial Hospital, Boston)
}

(Received for publication March 1, 1933)

In a previous communication (1) we have shown that thyroxin polypeptide has a calorigenic action identical to that of pure racemic thyroxin when the two are given, intravenously, in doses containing equal quantities of iodine. It was further shown that thyroxin polypeptide is as active when taken by mouth as when given intravenously. These facts can be taken advantage of for the further study of thyroid physiology. The present paper deals with the calorigenic activity of certain brands of whole thyroid gland, the calorigenic action of thyroxin polypeptide being used as a basis of comparison. The ultimate object is not to study the pharmacology of these drugs per se but to discover in what form the natural hormone circulates and is effective.

It is known that the organic iodine of whole thyroid gland is found partly in the form of thyroxin and partly in the form of diiodotyrosin (2). It has been shown by Thompson (3) and others (4) that diiodotyrosin exerts no calorigenic action in human myxedema even when given in very large doses. One would suppose therefore that the calorigenic action of whole thyroid would be determined by its thyroxin iodine rather than by its total organic iodine content. The data here presented prove that this supposition is incorrect.

Three patients with full-blown, untreated, spontaneous myxedema were given, daily, 15 grains (1.0 gram) of a lot of Armour and Company's thyroid, which had been found by analysis, according to Harington and Randall's method (5), to contain 0.05 per cent of thyroxin or so-called active iodine (the acid insoluble fraction) and 0.22 per cent of total organic iodine. ${ }^{1}$ The dosage of thyroid chosen contained $0.49 \mathrm{mgm}$. of thyroxin

1 At the outset of this investigation we were forced, in selecting our analytical method, to choose between the procedure of Harington and Randall (5) and of Leland and Foster (7). The latter method involves a twenty-four-hour alkaline hydrolysis, and gives lower values for thyroxin content. W. W. Palmer and co-workers $(8)$ have recently published data which indicate that the lower figures may be more accurate.

In view of the comparative newness of both procedures, it seemed to us 
iodine comparable to the amount present in one milligram of thyroxin polypeptide. This dose of thyroid contained $2.2 \mathrm{mgm}$. of total organic iodine. In Figure 1 the curves of these three assays are shown, together with the composite curve of five assays with thyroxin polypeptide given orally in the dosage of $1.0 \mathrm{mgm}$. daily. The thyroxin iodine is identical in all eight assays.

If now the calorigenic action of whole thyroid depends upon its thyroxin iodine alone the curves of the assays with fifteen grains of Armour's preparation should not have a significantly steeper slope than those of the polypeptide assays. As a matter of fact inspection of Figure 1 will show that they do, all three of them, have a distinctly steeper slope.

Approaching the problem from the other side we have also made assays with preparations containing far less thyroxin iodine than does one milligram of thyroxin polypeptide. Three such assays were made in three cases of full-blown, spontaneous, untreated myxedema using a daily dose of five and three-tenths grains orally of a lot of Armour's thyroid which had been found by analysis to contain (per dose given) $0.16 \mathrm{mgm}$. of thyroxin iodine and $0.69 \mathrm{mgm}$. of total organic iodine. The curves are shown in Figure 2.

It is to be noted that in these three assays the thyroxin iodine fraction was approximately one-third what it was in the polypeptide controls. Yet these curves not only are no less steep than those of the polypeptide group but two of them are definitely steeper, probably by virtue of the higher total organic iodine content of the dose used- $-0.69 \mathrm{mgm}$. versus $0.49 \mathrm{mgm}$.

We also have an assay of a daily oral dose of fifteen grains of a Burroughs, Wellcome preparation of thyroid which was found by analysis to contain (per dose given) $0.13 \mathrm{mgm}$. of thyroxin iodine and $0.77 \mathrm{mgm}$. of total organic iodine. This curve is also shown in Figure 2. It has precisely the same slope as the polypeptide control although the dose used contains only about one-quarter as much thyroxin iodine. The subject of this assay suffered from cachexia strumipriva, the result of the complete enucleation of a lingual goiter.

In the present communication it seems well also to include certain curves found in the earlier data of the Thyroid Clinic. A group of five is shown in Figure 3. These observations were all made in myxedematous patients and the daily oral dose of thyroid used was three grains of our stock Armour's preparation. The total organic iodine for the dose given was $0.42 \mathrm{mgm}$. The thyroxin iodine was not determined. The chief value of these curves is in the further evidence they give of the accuracy of the method of assay. These curves, shown in Figure 3, seem to us to be definitely less steep, having a slope of about 2.0 per cent per day, than those

expedient to use the method which gives higher values, i.e., the four-hour hydrolysis of Harington and Randall. The result would be a tendency to credit thyroid substance with a maximum amount of thyroxin, and in consequence strengthen the basis of our main thesis. 


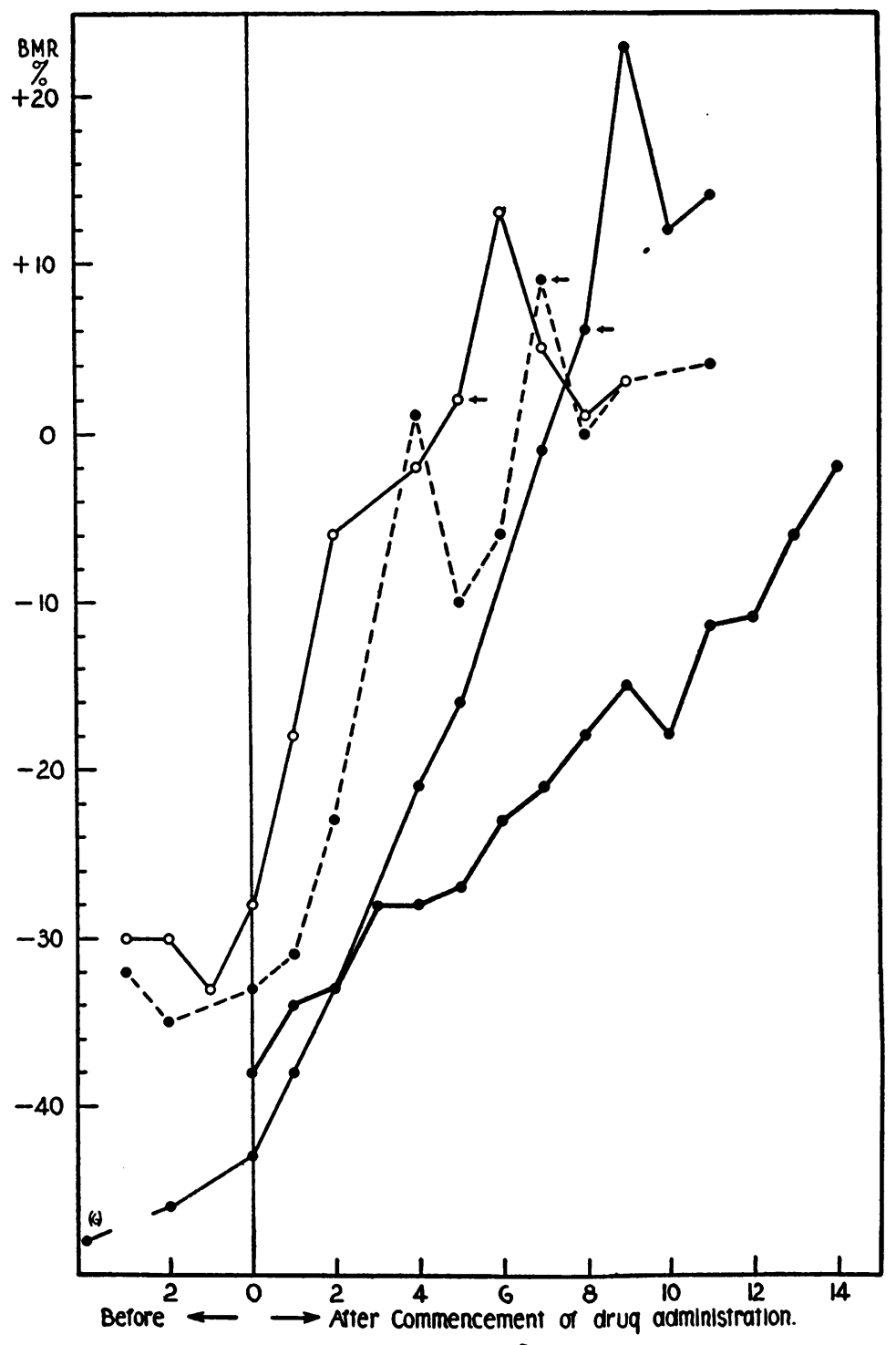

DAYS.

FIG. 1

The upper three curves are the calorigenic responses in three patients with spontaneous myxedema who received daily oral doses of thyroid gland containing $0.49 \mathrm{mgm}$. of thyroxin iodine and $2.2 \mathrm{mgm}$. of total organic iodine. The lowest curve given for comparison is the composite of five assays of thyroxin polypeptide given in daily oral doses containing $0.49 \mathrm{mgm}$. of iodine.

The small arrows on the upper three curves indicate cessation of medication. 


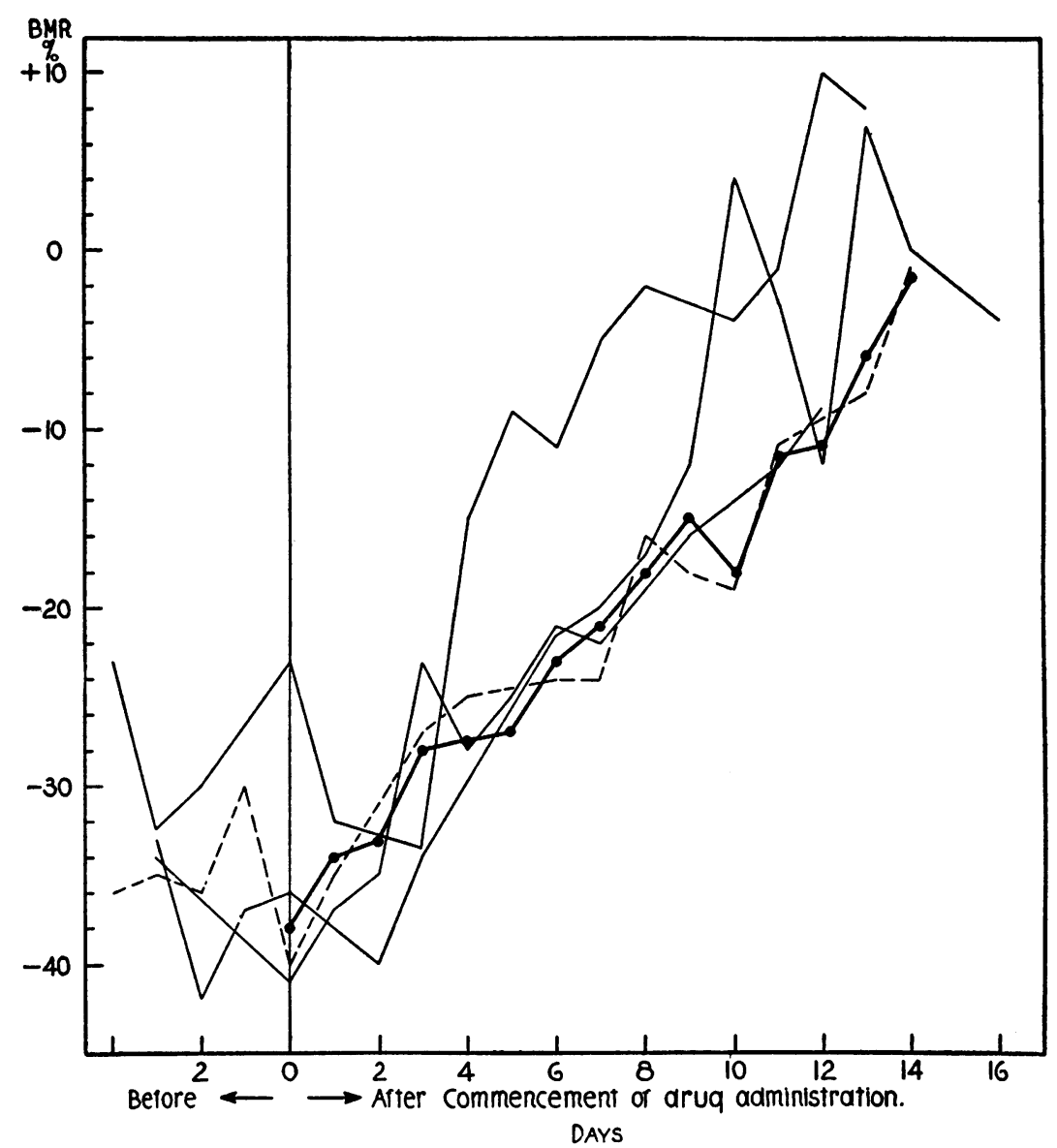

FIG. 2

The three curves shown by light solid lines are the calorigenic responses of three patients with spontaneous myxedema who received daily oral doses of a preparation of thyroid gland containing $0.16 \mathrm{mgm}$. of thyroxin iodine and 0.69 mgm. of total organic iodine.

The curve shown by the interrupted line is the response of a patient with cachexia strumipriva receiving a preparation of thyroid gland containing 0.13 $\mathrm{mgm}$. of thyroxin iodine and $0.77 \mathrm{mgm}$. total organic iodine. The heavy line is the same composite shown in Figure 1.

shown in Figure 2 in which the total organic iodine was between $0.69 \mathrm{mgm}$. and $0.77 \mathrm{mgm}$., which have an average slope of about 2.9 per cent per day. They are not far removed from the thyroxin polypeptide curve in spite of the fact that the thyroxin iodine content in the dose used was probably only about $0.1 \mathrm{mgm}$. The total organic iodine, on the other hand, was nearly that contained in the thyroxin polypeptide dosage, i.e. $0.42 \mathrm{mgm}$. versus $0.49 \mathrm{mgm}$. 


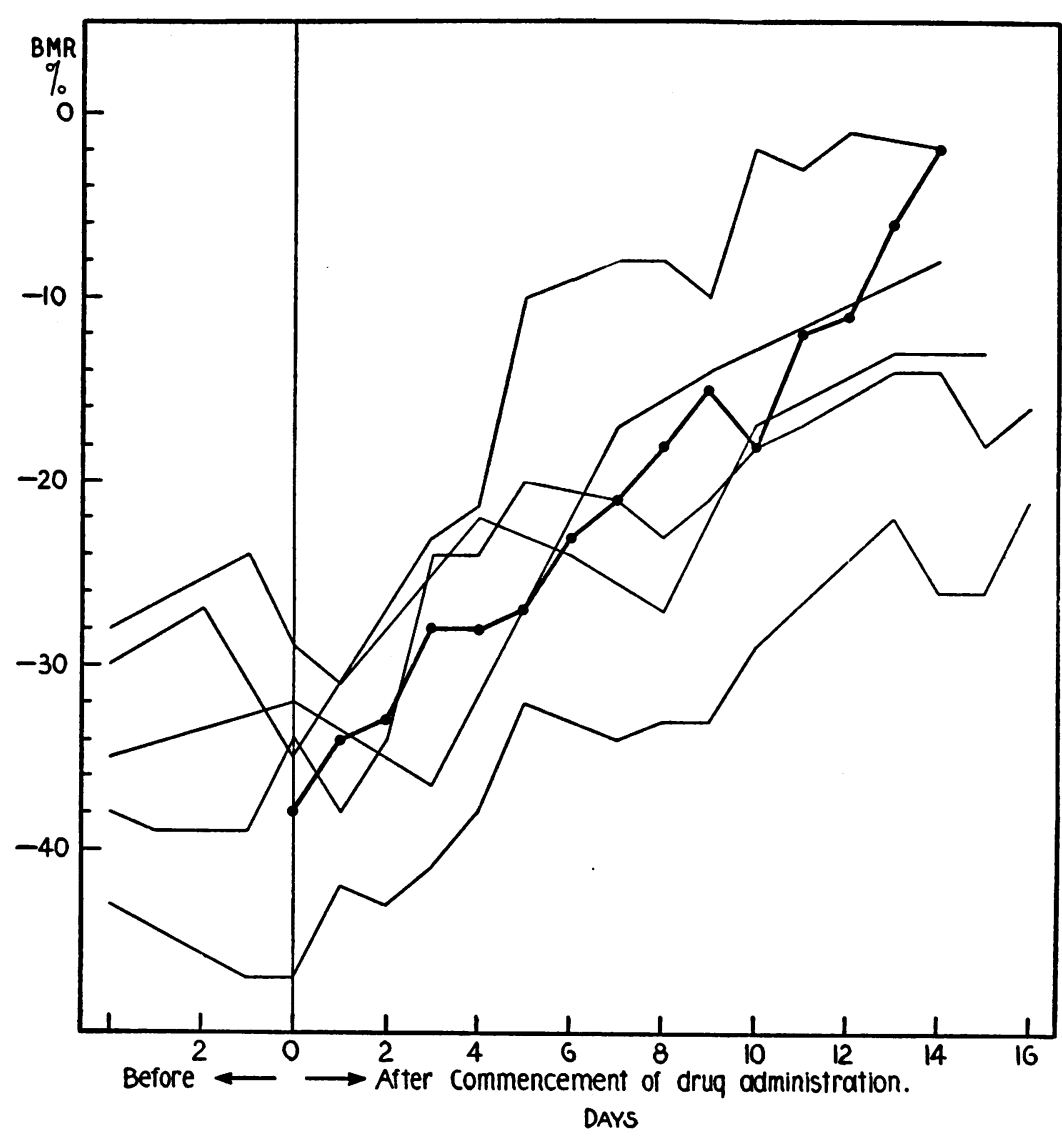

FIG. 3

Five calorigenic responses of patients with spontaneous myxedema who received daily oral doses of thyroid gland containing $0.42 \mathrm{mgm}$. of total organic iodine, shown by the light lines. The heavy line is the same composite as in Figures 1 and 2 .

Thus are we led to a paradox. The soluble fraction of iodothyroglobulin, which is diiodotyrosin, is inert when given alone yet exerts an action when given together with thyroxin in the form of whole gland. For this paradox we cannot at the moment offer an explanation but we are seeking one. The facts, we believe, are as we have stated. Additional proof that total organic rather than "active" iodine determines the calorigenic activity of whole gland has been obtained by a study of what constitutes an adequate maintenance ration when preparations. with different iodine contents are used. These observations will be published shortly (6). The work of Thompson (3) supplies proof of similar nature. 


\section{CONCLUSIONS}

The assay of preparations of whole thyroid gland of which the thyroxin or so-called active iodine (the acid insoluble fraction) and the total organic iodine had been determined shows that the calorigenic action of whole thyroid gland depends upon its total organic iodine rather than upon its thyroxin iodine content.

The mechanism by which diiodotyrosin assumes calorigenic properties when linked with amino acids in iodothyroglobulin remains a mystery.

\section{BIBLIOGRAPHY}

1. Salter, W. T., Lerman, J., and Means, J. H., J. Clin. Invest., 1933, xii, 327. The Calorigenic Action of Thyroxin Polypeptide.

2. Harington, C. R., and Randall, S. S., Biochem. J., 1929, xxiii, 373. Observations on the Iodine-containing Compounds of the Thyroid Gland. Isolation of d1-3: 5-diiodotyrosine.

3. Thompson, W. O., and Alper, J., 1932. Unpublished data.

4. Strouse, S., and Voegtlin, C., J. Pharmacol. and Exper. Therap., 1909, i, 123. Studies concerning the Iodine-containing Principle of the Thyroid Gland. I. Pharmacological Action and Therapeutic Behavior of Diiodotyrosin.

5. Harington, C. R., and Randall, S. S., Quart. J. Pharm. and Pharmacol., 1929, ii, 501. The Chemical Assay of Thyroid Gland.

6. Lerman, J., and Salter, W. T. Unpublished data.

7. Leland, J. P., and Foster, G. L., J. Biol. Chem., 1932, xcv, 165. A Method for the Determination of Thyroxine in the Thyroid.

8. Gutman, A. B., Benedict, E. M., and Palmer, W. W., Proc. Soc. Exper. Biol. and Med., 1932, xxix, 1198. Assay of Thyroid by Chemical Estimation of the Thyroxine Content. 